\title{
DEVELOPMENT OF BYPASSED OIL RESERVES USING BEHIND CASING RESISTIVITY MEASUREMENTS
}

\author{
Santa Fe Springs Field, Los Angeles County, California
}

Final Technical Progress Report

Reporting Period Start Date: February 14, 2004

Reporting Period End Date: $\quad$ February 14, 2006

Prepared By: $\quad$ Michael G. Conner, Terra Exploration and Production Company Jeffrey A. Blesener PE, Consulting Petroleum Engineer

April 2, 2006

DOE Solicitation No.: DE-PS26-02NT15377

DOE Award Identification No.: DE-FG26-03NT15435

TERRA EXPLORATION AND PRODUCTION COMPANY 1250 E. $23^{R D}$ - Second Floor SIGNAL HILL, CALIFORNIA 90755-3502 


\section{DISCLAIMER}

This report was prepared as an account of work sponsored by an agency of the United States Government. Neither the United States Government nor any agency thereof, nor any of their employees, makes any warranty, express or implied, or assumes any legal liability or responsibility for the accuracy, completeness, or usefulness of any information apparatus, product, or process disclosed, or represents that its use would not infringe privately owned rights. Reference herein to any specific commercial product, process, or service by trade name, trademark, manufacturer, or otherwise does not necessarily constitute or imply its endorsement, recommendation, or favoring by the United States Government or any agency thereof. The views and opinions of authors expressed herein do not necessarily state or reflect those of the United States Government or any agency thereof. 


\begin{abstract}
Tubing and rods of the S.P. Pedro-Nepple \#1 well were pulled and the well was prepared for running of Schlumberger's Cased Hole Formation Resistivity Tool (CHFR) in selected intervals. The CHFR tool was successfully run and data was captured. The CHFR formation resistivity readings were compared to original open hole resistivity measurements. Separation between the original and CHFR resistivity curves indicate both swept and un-swept sand intervals. Both watered out sand intervals and those with higher remaining oil saturation have been identified. Due to the nature of these turbidite sands being stratigraphically continuous, both the swept and unswept layers have been correlated across to one of the four nearby offset shallow wells. As a result of the cased hole logging, one well was selected for a workover to recomplete and test suspected oil saturated shallow sand intervals.

Well S.P. Pedro-Nepple \#2 was plugged back with cement excluding the previously existing production interval, squeeze cemented behind casing, selectively perforated in the shallower "Bell" zone and placed on production to develop potential new oil reserves and increase overall well productivity. Prior workover production averaged 3.0 BOPD for the previous six-months from the original "Meyer" completion interval. Post workover well production was increased to 5.3 BOPD on average for the following fifteen months. In December 2005, a bridge plug was installed above the "Bell" zone to test the "Foix" zone. Another cement squeeze was performed behind casing, selectively perforated in the shallower "Foix" zone and placed on production. The "Foix" test has produced water and a trace of oil for two months.
\end{abstract}




\section{TABLE OF CONTENTS}

Page

Executive Summary

5

Discussion

Experimental

7

$\begin{array}{ll}\text { Results and Discussion } & 9\end{array}$

$\begin{array}{ll}\text { Conclusion } & 12\end{array}$

$\begin{array}{ll}\text { References } & 13\end{array}$

List of Acronyms and Abbreviations $\quad 14$

$\begin{array}{ll}\text { List of Graphical Materials } & 15\end{array}$

1. CHFR log example - Bell Zone 15

2. CHFR log example - Foix Zone 16

3. S.P. Pedro-Nepple \#2 Production Plot 17 


\section{EXECUTIVE SUMMARY}

Potential oil reserves remain in selected turbidite sand sequences of the Santa $\mathrm{Fe}$ Springs Field in Los Angeles County, California. Many productive zones of the field have been waterflooded where more permeable sand layers have preferentially watered out. It is suspected the flood fronts have bypassed lower permeable, yet oil saturated sand intervals. Due to low salinity formation water, more conventional TDT logs are not suitable in detecting hydrocarbons behind cemented casing. The project uses casedhole resistivity measurements to identify higher oil saturated sands. Up to four wells may be perforated and placed on production to develop behind-flood-front oil sands in marginal stripper production wells if initial testing is economic. If lower-sand potential exists, one well may be deepened.

There are five active producing wells in the "Pedro-Nepple" and "Fulton" leases of the Santa Fe Springs Field. Four of the five wells range in depth from 3,841 feet to 4,505 feet. The deep well, S.P. Pedro-Nepple \#1, has a total depth of 10,152 feet, thereby penetrating all of the sand intervals of the four offsetting shallow production wells.

Tubing and rods of the S.P. Pedro-Nepple \#1 well were pulled and the well was prepared for running of Schlumberger's Cased Hole Formation Resistivity Tool (CHFR) in selected intervals. The CHFR formation resistivity readings were compared to original open hole resistivity measurements. Separation between the original and CHFR resistivity curves indicate both swept and un-swept sands. Both watered out sand intervals and those with higher remaining oil saturation have been identified. Due to the nature of the turbidite sands being stratigraphically continuous, both the swept and unswept layers have been correlated across to one of the four nearby offset shallow wells. As a result of the cased hole logging, up to four well workover projects have been identified. One of these four wells, S.P. Pedro-Nepple \#2, was plugged out of the existing interval, cement squeezed, and selectively perforated. The project tested two zones ("Bell" and "Foix") separately. The well was placed on production to test potential new oil reserves and increase overall well productivity.

Approximately six potential pay zones were evaluated using the CHFR tool in the S.P. Pedro-Nepple \#1 well. The following table outlines the zones, approximate CHFR logged footage and potential pay intervals:

\begin{tabular}{|c|c|c|}
\hline Logged Zone & Logged Depths, Ft. & Potential Pay \\
\hline Shallow Gas & $2265-2329$ & Yes, 2282-2292 \\
\hline Terra & $3060-3226$ & Yes, 3071-3120 \\
\hline Foix & $3464-3625$ & Yes, 3478-3496 \\
\hline Bell & $3858-3990$ & Yes, 3887-3935 \\
\hline Meyer & $4311-4640$ & No \\
\hline
\end{tabular}


Many, if not all, of the offset wells will require remedial circulation or block cement squeezes performed to isolate the proposed recompletion intervals prior to perforation. Many, if not all, of the offset wells did not have primary cement displaced high enough to cover the potential recompletion zones that the CHFR log identifies.

In May 2004, a workover program to recomplete a shallow zone identified by the CHFR log was completed in well S.P. Pedro-Nepple \#2. The well was plugged back with cement excluding the previously existing production interval in a deeper zone, squeeze cemented behind casing, selectively perforated in the shallower "Bell" zone and placed on production to develop potential new oil reserves identified by the CHFR log and increase overall well productivity. Since the well did not have primary cement behind casing high enough to exclude water sands, a circulation cement squeeze was attempted to isolate the target zone. Even though the circulation cement squeeze operation went well and according to program, an ensuing CBL showed less than desirable bonding across the target interval. It was decided to move forward without doing any additional secondary block squeeze cementing. Approximately 4, 0.4-inch holes-per-foot jet perforations were shot the two prospective intervals identified by the CHFR log from $3935^{\prime}$ to 3927 ' and 3917 ' to $3912^{\prime}$.

Prior workover production averaged 3.0 BOPD for the previous six-months from the original "Meyer" completion interval. Post workover well production was marginally increased to 5.3 BOPD on average for the following fifteen months. The project has resulted in an incremental cumulative production of approximately 835 barrels of oil with no significant increase in water production. In December 2005, a bridge plug was installed above the "Bell" zone to test the "Foix" zone. Another cement squeeze was performed behind casing, selectively perforated in the shallower "Foix" zone. Approximately 4, 0.4-inch holes-per-foot jet perforations were shot in the prospective interval identified by the CHFR log from 3477' to 3492' and placed on production. The "Foix" test has produced water and a trace of oil for two months. 


\section{EXPERIMENTAL}

In an active waterflood, determining the flood-front position usually requires the use of open hole resistivity logs. This method works well in a field that has an active infilldrilling program where new open hole log data can be obtained at regular intervals over time. Traditional cased-hole logs have been inconclusive as flood-front monitoring tools.

Pulsed neutron tools, such as the carbon/oxygen and thermal-decay rate tools (TDT), also have limited application and provide inconclusive results. The low salinity of the formation and injected water has made it difficult for the thermal-decay rate tools to discern oil from the water phase ${ }_{2}$.

\section{The Cased Hole Resistivity (CHFR) Tool}

Schlumberger Well Services has developed a commercially available tool that measures formation resistivity in cased holes 3 . The resistivity measurement is made independently of the salinity of the formation fluid and porosity. The depth of investigation is substantially beyond the near wellbore, beyond the influence of flushing from drilling mud filtrate. Other applications include using this tool to log wells through casing in older wells where open hole logs were not available at the time.

The CHFR is a pad contact-type tool where the logging sonde must come to a complete rest within the well in order to establish electrical coupling with the existing well casing. As the tool stops at each depth, the contact pads couple with the casing and directly measure formation resistivity for that single depth. Each stop represents one resistivity measurement. Therefore, several stops must be made approximately $2-4$ feet apart in selected intervals of interest in order to develop a potential pay zone resistivity profile. According to the tool vendor, each stop and respective measurement takes approximately 3-5 minutes to obtain a reading. The tool does not accurately measure behind casing resistivity at the casing collars, so the tool must be either raised or lower accordingly.

The CHFR log was run successfully on January 10-11, 2004. The logging engineer had some difficulties testing the tool on the surface, extending and contracting the contact pad apparatus. Following these difficulties, the tool had no other problems running in and out of the 7 -inch cased hole.

Once logging commenced with a formation resistivity measurement at each stop of the tool, it became apparent the tool logging speed is slower than we anticipated. The time duration at each stop varied and required between 4-8 minutes for the tool to stabilize and measure consistent readings. There were numerous times the tool could not measure formation resistivity due to a stop that coincided at a casing collar. The tool would then be moved either up or down a couple feet and successfully measured. 


\section{Approximate Gross Footage of Logged Interval}

\begin{tabular}{|c|c|c|c|c|c|}
\hline & & & & & Original \\
\hline Log Interval Depths & Feet & Potential Pay Interval & Feet & Zone & Resist. ohm-m \\
\hline $7950-7900$ & 50 & $7940-7924$ & 26 & Hathaway & 13.5 \\
\hline $7560-7500$ & 60 & $7552-7510$ & 42 & O'Connell & $7-9.5$ \\
\hline $7450-7400$ & 50 & $7447-7415$ & 32 & O'Connell & 9.5 \\
\hline $4620-4530$ & 90 & $4607-4530$ & 77 & Meyer (M6) & $8-40+$ \\
\hline $4515-4425$ & 90 & $4508-4430$ & 78 & Meyer (M5) & $11-16$ \\
\hline $4400-4320$ & 80 & $4396-4335$ & 61 & Meyer (M3) & $70-80$ \\
\hline $3975-3880$ & 95 & $3920-3885$ & 65 & Bell & $13.5-16$ \\
\hline $3515-3470$ & 45 & $3511-3477$ & 34 & Foix & 20 \\
\hline $3180-3070$ & 110 & $3172-3072$ & 100 & $?$ & $9-14$ \\
\hline $2310-2270$ & 40 & $2305-2276$ & 29 & Gas? & 11.5 \\
\hline & & & & & \\
\hline & 710 & & 544 & & \\
\hline
\end{tabular}

Approximately 580 resistivity measurement stops were made to evaluate the 710 feet of intervals listed above. Some of the intervals include sections with numerous hard, cemented, calcareous sands commonly called 'bones' or 'shells' that are very resistive. Not having a porosity log for the original open hole, it is difficult to discern the higher resistivity intervals as these hard streaks from oil saturated pay sands. Given a choice, candidate well selection should include a well where porosity logs are available.

The CHFR formation resistivity readings were compared to original open hole resistivity measurements. Separation between the original and CHFR resistivity curves indicate both swept and un-swept sand intervals. Both watered out sand intervals and those with higher remaining oil saturation have been identified. Due to the nature of these turbidite sands being stratigraphically continuous, both the swept and unswept layers have been correlated across to one of the four nearby offset shallow wells.

\section{Well S.P Pedro-Nepple \#2 Workover}

Since there are some unmapped faults in the area, a well nearest the S.P. PedroNepple \#1 well was desired to be recompleted into a shallow zone. The nearest offset well, S.P. Pedro-Nepple \#2 has been plugged back with cement excluding the previously existing production interval in a deeper zone, squeeze cemented behind casing, selectively perforated in the shallower "Bell" zone and placed on production. Since the well did not have primary cement behind casing high enough to exclude water sands, a circulation cement squeeze was attempted to isolate the target zone. Even though the circulation cement squeeze operation went well and according to program, an ensuing CBL showed less than desirable bonding across the target interval. It was 
decided to move forward without doing any additional secondary block squeeze cementing. Approximately 4, 0.4-inch holes-per-foot jet perforations were shot the two prospective intervals identified by the CHFR log from 3935' to 3927 ' and 3917 ' to $3912^{\prime}$.

Prior workover production averaged 3.0 BOPD for the previous six-months from the original "Meyer" completion interval. Post workover well production was marginally increased to 5.3 BOPD on average for the following fifteen months. The project has resulted in an incremental cumulative production of approximately 835 barrel of oil with no significant increase in water production. In December 2005, a bridge plug was installed above the "Bell" zone to test the "Foix" zone. Another cement squeeze was performed behind casing, selectively perforated in the shallower "Foix" zone. Approximately 4, 0.4-inch holes-per-foot jet perforations were shot in the prospective interval identified by the CHFR log from 3477' to 3492' and placed on production. The "Foix" test has produced water and a trace of oil for two months. 


\section{RESULTS AND DISCUSSION}

Tubing and rods of the S.P. Pedro-Nepple \#1 well were pulled and the well was prepared for running of Schlumberger's Cased Hole Formation Resistivity Tool (CHFR) in selected intervals. The CHFR log was run successfully on January 10-11, 2004. The logging engineer had some difficulties testing the tool on the surface, extending and contracting the contact pad apparatus. Following these difficulties, the tool had no other problems running in and out of the 7 -inch cased hole.

The CHFR formation resistivity readings were compared to original open hole resistivity measurements. Separation between the original and CHFR resistivity curves indicate both swept and un-swept sands. Both watered out sand intervals and those with higher remaining oil saturation have been identified. Due to the nature of the turbidite sands being stratigraphically continuous, both the swept and unswept layers have been correlated across to one of the four nearby offset shallow wells. As a result of the cased hole logging, up to four well workover projects have been identified.

Approximately six potential pay zones were evaluated using the CHFR tool in the S.P. Pedro-Nepple \#1 well.

\section{Approximate CHFR Logged Footage and Potential Pay Intervals}

\begin{tabular}{|c|c|c|}
\hline Logged Zone & Logged Depths, Ft. & Potential Pay \\
\hline Shallow Gas & $2265-2329$ & Yes, 2282-2292 \\
\hline Terra & $3060-3226$ & Yes, 3071-3120 \\
\hline Foix & $3464-3625$ & Yes, 3478-3496 \\
\hline Bell & $3858-3990$ & Yes, 3887-3935 \\
\hline Meyer & $4311-4640$ & No \\
\hline O-Connell & $7344-7588$ & Possible, 7510-7520 \\
\hline
\end{tabular}

Many, if not all, of the offset wells will require remedial circulation cement squeezes performed to isolate the proposed recompletion intervals prior to perforation. Many, if not all, of the offset wells did not have primary cementing displaced high enough to cover the potential recompletion zones that the CHFR log identifies. In order to test the CHFR logging results, one of these four wells, S.P. Pedro-Nepple \#2, was plugged out of the existing interval, cement squeezed and selectively perforated in the "Bell" zone and placed on production to develop potential new oil reserves and increase overall well productivity. Since the well did not have primary cement behind casing high enough to exclude water sands, a circulation cement squeeze was attempted to isolate the target zone. Even though the circulation cement squeeze operation went well and according to program, an ensuing CBL showed less than desirable bonding across the target interval. It was decided to move forward without doing any additional secondary block squeeze cementing. Approximately 4, 0.4-inch holes-per-foot jet perforations were shot 
the two prospective intervals identified by the CHFR log from 3935' to $3927^{\prime}$ and $3917^{\prime}$ to 3912 .

Prior workover production averaged 3.0 BOPD for the previous six-months from the original "Meyer" completion interval. Post workover well production was marginally increased to 5.3 BOPD on average for the following fifteen months. The project has resulted in an incremental cumulative production of approximately 835 barrel of oil with no significant increase in water production. In December 2005, a bridge plug was installed above the "Bell" zone to test the "Foix" zone. Another cement squeeze was performed behind casing, selectively perforated in the shallower "Foix" zone. Approximately 4, 0.4-inch holes-per-foot jet perforations were shot in the prospective interval identified by the CHFR log from 3477' to 3492' and placed on production. The "Foix" test has produced water and a trace of oil for two months. 


\section{CONCLUSION}

In January 2004, the CHFR cased hole tool was successfully run and measured formation resistivity through 7-inch casing in an older Santa Fe Springs Field production well. The CHFR appears to have identified four potential pay intervals in shallower zones, above the existing production intervals in the existing lease wells. Potential pay intervals could be correlated stratigraphically to the offset wells where recompletion opportunities may increase reserves and overall productivity.

Initially, the tool had some mechanical difficulties, but this was addressed and no other problems occurred. The logging speed is slow as the tool is not continuously reading and recording. The tool must come to complete rest, making direct contact with the casing, measuring formation resistivity through the casing string.

When an infill drilling program is not practical to track flood fronts, the tool indicates it is capable of determining behind casing formation resistivity, therefore, water saturation. Some of the intervals include sections with numerous hard, cemented, calcareous sands commonly called 'bones' or 'shells' that are very resistive. Not having a porosity log for the original open hole, it is difficult to discern the higher resistivity intervals as these hard streaks from oil saturated pay sands. Given a choice, candidate well selection should include a well where porosity logs are available.

In May 2004, well S.P. Pedro-Nepple \#2 was plugged back with cement excluding the previously existing production interval in a deeper zone, squeeze cemented behind casing, selectively perforated in the shallower "Bell" zone and placed on production to test potential new oil reserves identified by the CHFR log and increase overall well productivity. Even though the results of the CHRF log indicated the presence of movable hydrocarbons, the resulting production from the workover is less than anticipated. Additionally, a second test of another promising interval in the "Foix" zone proved to be unsuccessful as the interval from 3477' to 3492' produced water and a trace of oil for two months. It is possible the cement squeeze performed across the "Foix" zone was unsuccessful in excluding water and is not representative of the oil production potential. 


\section{REFERENCES}

1. California Division of Oil, Gas and Geothermal Resources, Summary of Operations - California, Vol. 43, No.2, 1957.

2. M. Starcher, D. Mut, M. Fontanarosa, B. Davis, C. Presmyk. "Waterflood Surveillance: Behind Casing Resistivity Measurement at Elk Hills", Society of Petroleum Engineers, Journal of Petroleum Technology, October 2002.

3. Schlumberger Internet website:

http://www.oilfield.slb.com/content/services/formation/analysis/chfr.asp 


\title{
LIST OF ACRONYMS AND ABBREVIATIONS
}

\author{
BOPD - Barrels Oil Per Day \\ $\mathrm{CBL}$ - Cement Bond Log \\ CCL - Casing Collar Log \\ CHFR - Cased Hole Formation Resistivity tool \\ DOGGR - California Division of Oil, Gas and Geothermal Resources \\ GR - Gamma Ray \\ $\mathrm{OH}$ - Open Hole \\ TDT - Thermal Decay Tool \\ USI - Ultra-Sonic Imager
}




\section{GRAPHICAL MATERIALS}

1. CHFR log example - Bell Zone (Logged date: January 11, 2004)

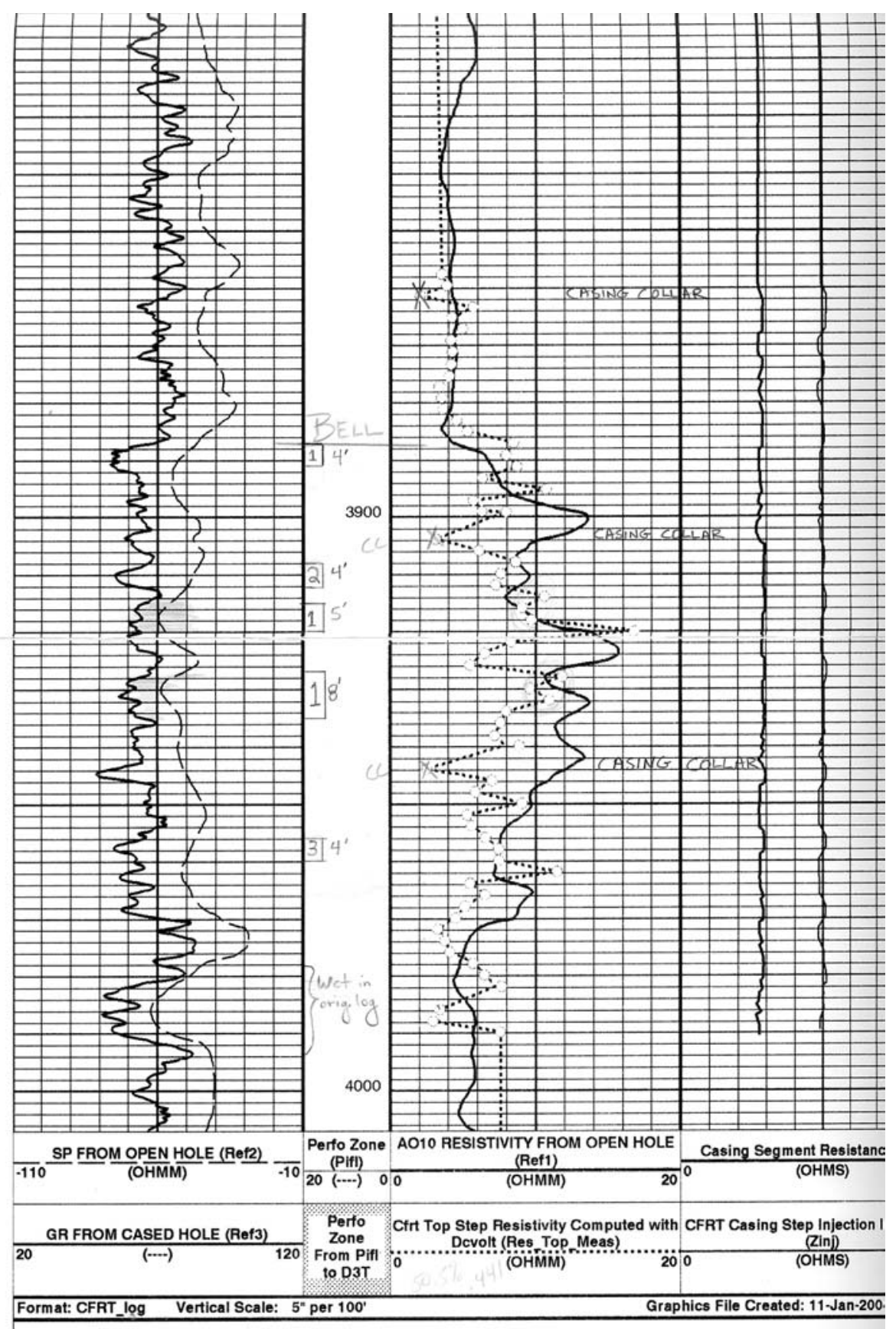


2. CHFR log example - Foix Zone (Logged date: January 11, 2004)

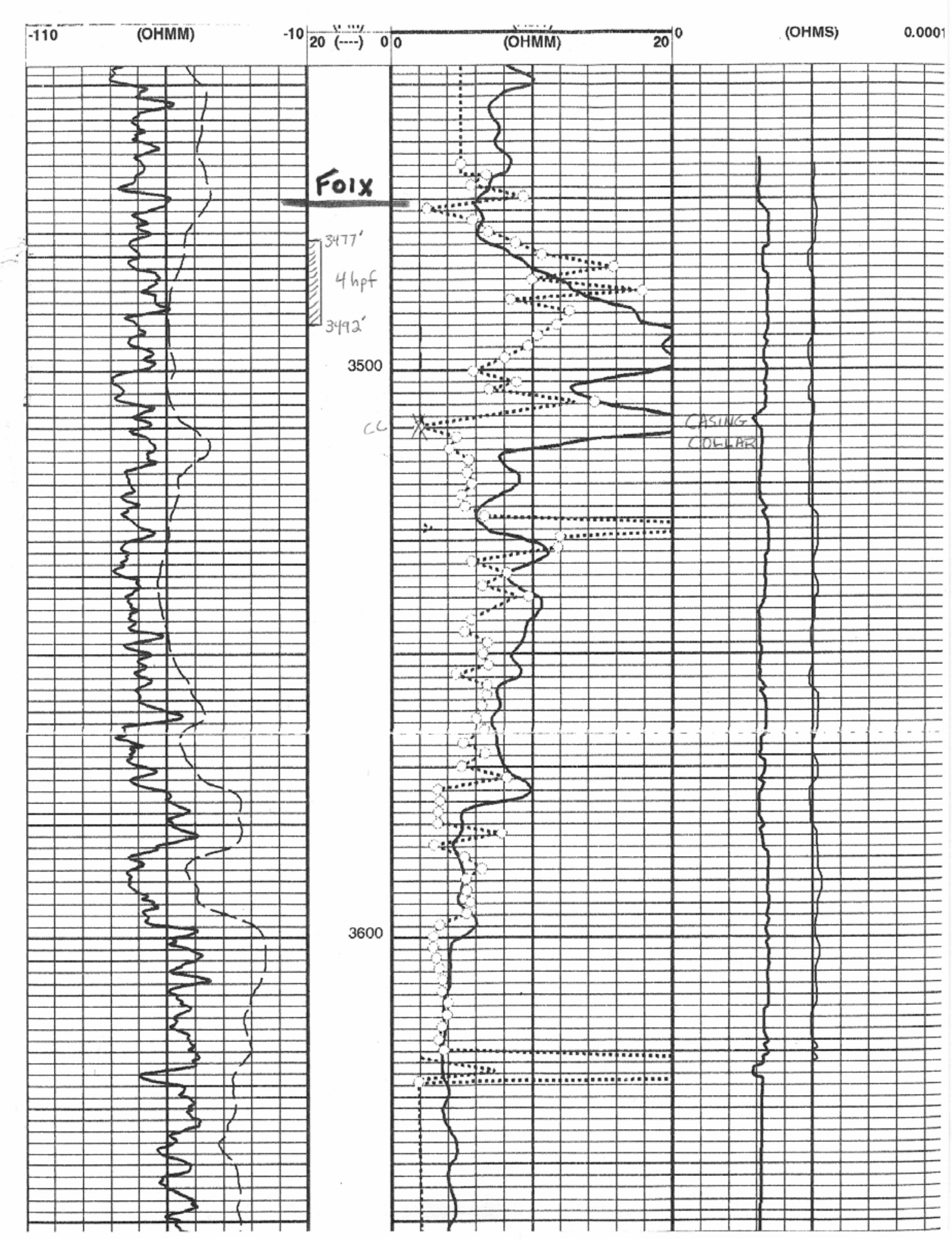


3. S.P. Pedro Nepple \#2 Production Plot

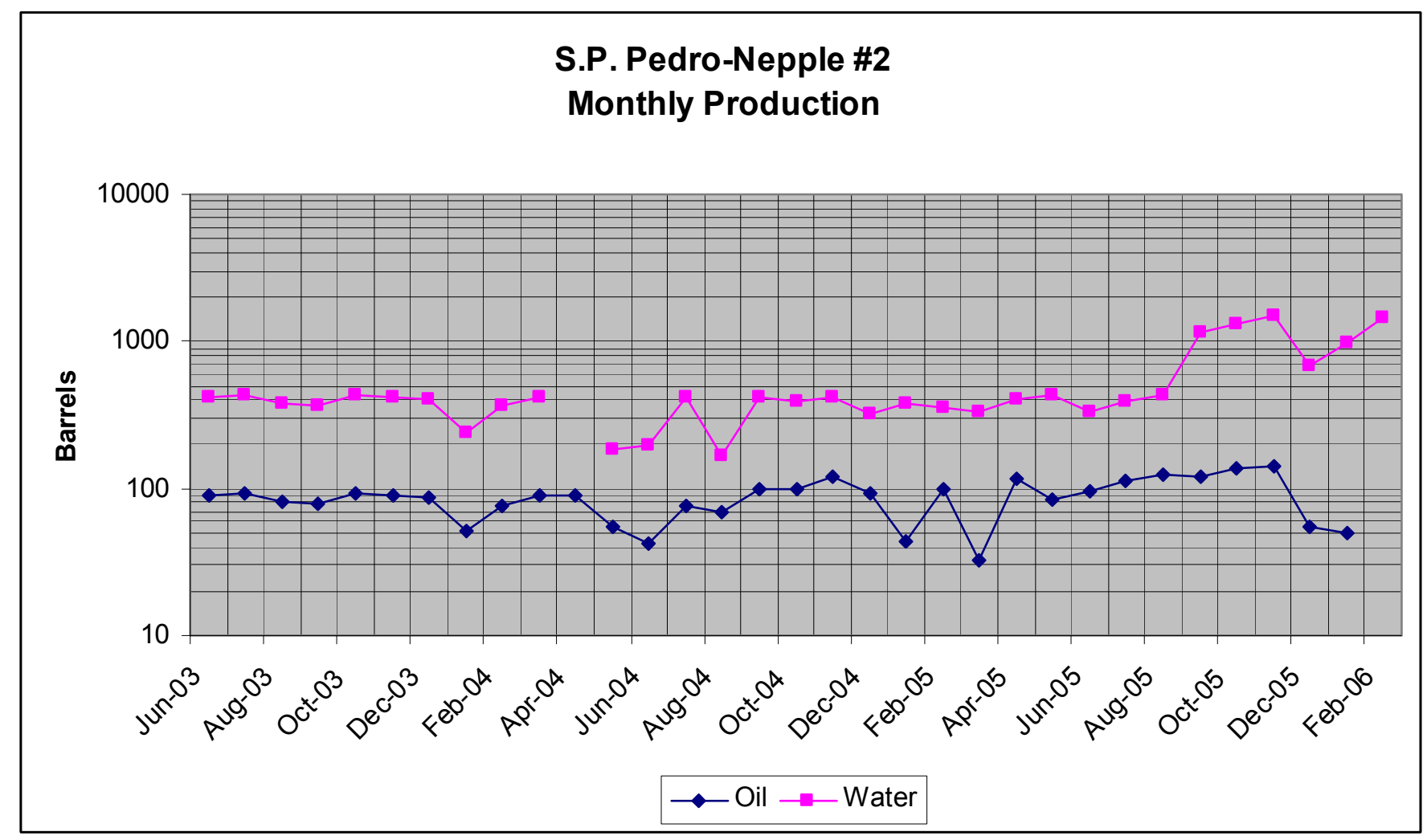

Recompletion workover occurred in May 2004. Daily oil production has marginally increased to 5.3 BOPD from the previous 3.7 BOPD. 